r. The age incidence is lower.

2. The pouches are often solitary.

3. The pouches are peculiarly liable to cause acute symptoms. Acute diverticulitis of the caecum, which closely resembles acute appendicitis in its clinical features, may, in fact, be the first indication of the presence of a pouch. Rarely, chronic inflammation of a diverticulum causes a mass in the right iliac fossa which is liable to be mistaken for cancer and the true nature of which only comes to light after excision.

The management of a case of acute diverticulitis revealed at operation undertaken on a diagnosis of acute appendicitis will vary according to the findings. There have been cases recorded in which the inflamed diverticulum was readily seen and was excised. In others there is found a mass of inflammatory tissue and the wall of the caecum itself is acutely inflamed. The best procedure for the latter condition is to exteriorize the bowel, with subsequent excision and, finally, closure. This is a protracted and irksome experience for the patient, but there appears to be no alternative.

\section{Diverticula of the Appendix}

Diverticula of the appendix may be demonstrated in about $\frac{1}{2}$ per cent. of appendices removed at operation. They may be associated. with generalized diverticulosis of the colon or may result from disorganization of the appendix musculature as a result of chronic fibrosis. They are not in themselves of any notable clinical significance.

\section{BIBLIOGRAPHY}

EDWARDS, H. C. (1939), Diverticula of the Small and Large Intestine, John Wright \& Sons, Bristol.

KRON, S. D., and SPECTER, J. (1950), Gastroenterology, $15,62$. MAYFIELD, L. H., and WAUGH, J. M. (1949), Ann. Surg., 129, 198.

MAYFIELD, L. H., and WAUGH, J. M. (1949), Ibid., 130, 186.

ORR, I. M., and RUSSELL, J. Y. W. (1951), Brit. F. Surg., 39, 139.

WALKER, R. M. (1945), Brit. F. Surg., 32, 457.

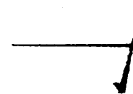

\title{
THE TREATMENT OF NEUROSYPHILIS
}

By C. S. Nicol, M.D., M.R.C.P.

Medical Officer in Charge, Special Treatment Centre, St. Bartholomew's Hospital : Assistant Physician. Whitechapel Clinic, London Hospital

In a paper dealing with the treatment of neurosyphilis, it is first necessary to discuss briefly the incidence, clinical classification and natural history of the condition.

It is almost certain that 'invasion' of the nervous system by the treponema pallidum occurs during the primary stage of the disease in all cases, but in the majority these organisms do not survive to produce an inflammatory process, thus 'involvement' may occur in 25 to 35 per cent. of cases. This involvement is first manifested by a pleocytosis and increased protein content of the spinal fluid in the secondary stage of the disease as demonstrated by the pioneer work of Ravaut (1903). Even after involvement of the nervous system at this stage spontaneous regression occurs in a number of cases so that Bruusgaard's (1929) analysis of patients with untreated syphilis seen many years later, gave a figure of 9.5 per cent. for those with neurosyphilis, while Rosahn's (1946) analysis of autopsy findings in 77 patients with untreated syphilis showed pathological evidence of neurosyphilis in 7.6 per cent.
A classification of neurosyphilis is always difficult as the involvement of meninges, vessels and parenchyma never occurs alone, but one or other type usually predominates.

I. Early syphilis (within first four years of infection):

(a) Asymptomatic neurosyphilis.

(b) Acute syphilitic meningitis (may occur in secondary stage or later).

2. Late syphilis (after fourth year of infection):

(a) Asymptomatic neurosyphilis.

(b) Meningeal syphilis of brain or spinal cord (often termed meningo-vascular as there is also involvement of smaller vessels).

(c) Vascular syphilis of brain or spinal cord (involvement of medium-sized vessels).

(d) Parenchymatous:

(i) General paresis.

(ii) Tabes dorsalis.

(iii) Optic atrophy.

(e) Gumma of brain or spinal cord.

It is important to know something of the natural history of neurosyphilis and realize that reversal 
Early' Syphilis

Asymptomatic Neurosyphilis

\section{A}

Asymptomatic

Late Syphilis

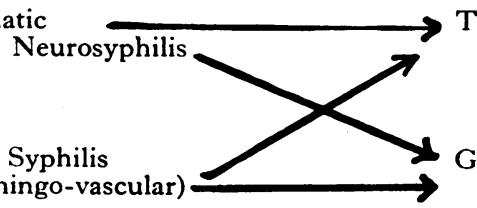

Meningeal Syphilis

(meningo-vascular)
Tabes Dorsalis

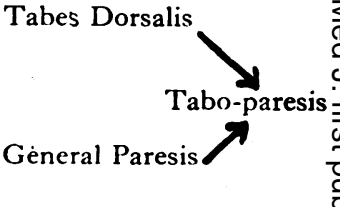

of the spinal fluid to normal can occur in both symptomatic and asymptomatic conditions. Progression is the rule with involvement of the parenchyma of the brain or spinal cord. This is indicated in Table $\mathrm{I}$.

In considering the curative effect of any drug in neurosyphilis it is most important to realize that this is very different in inflammatory (meningeal) and degenerative (parenchymatous) lesions. There may be complete resolution of inflammatory lesions with treatment as one sees in asymptomatic and meningo-vascular neurosyphilis, on the other hand if a degenerative lesion predominates as in tabes dorsalis, signs and symptoms may remain unchanged.

In some conditions, such as general paresis or Erb's spastic paraplegia, both types of lesions may be present. Gummatous lesions are of the inflammatory type, while the results of vascular neurosyphilis are mainly degenerative. If these facts are realized it is easier to assess the response to treatment in the various types of neurosyphilis. It is also a general rule that inflammatory lesions occur earlier in the course of the disease than degenerative lesions, and thus early treatment (ideally in the asymptomatic phase) will give the best results.

Examination of the cerebro-spinal fluid is essential in neurosyphilis, both in diagnosis and in order to assess the results of treatment. This involves four tests: (a) the cell count; (b) the estimation of total proteins; $(c)$ the spinal fluid Wassermann reaction; (d) Lange's colloidal gold curve. A test for increase in globulin (Pandy test) is not essential as the colloidal gold test is an indication of the albumen globulin ratio in the spinal fluid.

(a) An increase in the cell count above 3 to 5 per cu.mm. is the earliest indication of involvement of the nervous system by the treponema pallidum, and equally it is the first test to revert to normal as a result of treatment.

(b) An increase in the total protein above 40 mgm. per cent. follows an increased cell count, and it also is the next test to revert to normal with treatment.

(c) The Wassermann reaction takes longer to become positive and is slow to reverse with treatment; it may take several years to revert to negative. Thus retreatment is not necessarily indicated if this test remains positive provided the $\frac{\vec{\phi}}{\partial}$ cell count and protein revert to normal. $A \stackrel{2}{\circ}$ quantitative Wassermann test is helpful as it $\omega$ indicates the gradual fall in titre. False positive $\overrightarrow{0}$ reactions of the Wassermann test in the spinal fluid $\vec{\overrightarrow{ }}$ are rare, except in the presence of bacterial $\vec{\sigma}$ meningitis, when the ' reagin' from the blood may음 pass through the choroid plexus provided, of course, that the patient already has latent syphilis.

(d) The colloidal gold test parallels the Wassermann test in the rate of appearance of abnormal curves and their modification and reversal to normal with treatment. Dattner (1944) has emphasized that the so-called paretic, luetic and meningitic curves do not necessarily indicate the conditions named. They may all occur in asymptomatic neurosyphilis, and a paretic patient may have a luetic curve and vice versa. It is probable, however, that the presence of a paretic $\vec{\theta}$ curve in a patient with asymptomatic neure of syphilis suggests that that patient, if untreates would develop general paresis. In 1944 Lang and Harris introduced a new method for the colloidal gold test by which the colour changes were constant and the numerical value given to each would be totalled so as to produce a quantita- $\triangle$ tive as well as a qualitative test.

Using these basic tests, spinal fluid findings in $\frac{0}{3}$ neurosyphilis are usually classified in three groups.

Group I. Cases with abnormal cell count and total protein with a negative colloidal gold and Wassermann test.

Group 2. All cases not included in Group I or Group 3.

Group 3. Cases with abnormal cell count and $\delta$ total protein, positive Wassermann test and a paretic type of colloidal curve.

\section{Dattner Thomas Concept}

Dattner and Thomas (1942) believe that the cure of a patient with neurosyphilis is assured if $\sigma$ all the tests in the spinal fluid become and remain $N$ negative. They assume that this indicates resolu- N tion of the meningeal inflammatory process and believe that while any degenerative process cannot

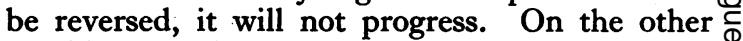
hand in tabes dorsalis and optic atrophy this is not $\stackrel{\oplus}{?}$ always the case.

In contrast to the reversal of an abnormal spinal ${ }^{\circ}$ fluid produced by adequate therapy, the blood 
serological tests (Wassermann and Kahn reactions) remain positive in the majority of cases. Quantitive tests will demonstrate variations in titre according to certain patterns (Redmond, Nicol and Shooter, 1952). 'Seroresistance' is of no prognostic significance and does not indicate further treatment of the neurosyphilis.

\section{General Considerations of Therapy}

Before the discovery of penicillin, neurosyphilis was treated with various combinations of neoarsphenamine, bismuth, tryparsamide and fever therapy (benign tertian malaria or mechanical fever). Since the introduction of penicillin all are agreed that this is the drug of choice. There are still, however, a number of controversial points to be decided.

I. The type of penicillin, dosage and duration of course. In most clinics at present the procaine salt of penicillin is used. This saves multiple injections and may be given once daily intramuscularly in dosage ranging from 0.5 to 1.0 mega unit. A course of injections may last for to to I 5 days, giving a range of from 5.0 to $15.0 \mathrm{mega}$ units total dosage.

2. The mechanism of the Farisch Herxheimer reaction and possible means of preventing it. Heyman, Sheldon and Evans (1952) now consider the Herxheimer reaction to be a hypersensitivity phenomenon of the delayed type. This reaction, as manifested by a rise in rectal temperature above $100^{\circ} \mathrm{F}$. following the first injection of penicillin, is not uncommon in all types of neurosyphilis and may occur in about half the cases of general paresis treated. It is uncommon, however, to get a severe reaction with exacerbation of symptoms or the appearance of new symptoms. In this country the present policy is to give 6 to 12 weeks preparatory treatment with intramuscular bismuth ( 0.2 to $0.4 \mathrm{~g}$. each injection) in the hope of preventing a reaction. While the resultant delay in giving the penicillin is not important in most cases of neurosyphilis, it may be thought advisable that acute syphilitic meningitis or general paresis of acute onset should be treated immediately with penicillin and the small risk of a serious Herxheimer reaction accepted. The evidence from the work of Farmer (1948) suggests that giving initial small doses of penicillin in no way prevents a Herxheimer reaction, thus when a course of penicillin is started initially or after bismuth therapy it may be given in full dosage.

3. The indications for adjuvant fever therapy. In 1946 the situation was summarized by Moore as follows:

Penicillin alone is indicated in early asymptomatic neurosyphilis, meningo-vascular neuro- syphilis, vascular neurosyphilis and gumma of the brain and cord.

Penicillin plus fever therapy is indicated in general paresis, tabo paresis, primary optic atrophy, eighth nerve deafness, syphilitic epilepsy and Erb's spastic paraplegia.

The best type of fever therapy is induced malaria, 8 to 12 paroxysms ( 40 to 60 or more hours of fever over $104^{\circ} \mathrm{F}$.).

Hahn (195I) summarizes the present trend as follows:

Although opinions to the contrary are expressed the consensus appears to be that in all forms of neurosyphilis, with the exception of primary optic atrophy, the clinical and spinal fluid results of treatment with penicillin alone are comparable to those with penicillin plus fever therapy.

\section{Early Syphilis (First Four Years of Infection)}

(a) Asymptomatic neurosyphilis. Excellent results as judged by spinal fluid reversal are obtained with penicillin alone. Hahn (195I) reports 100 per cent. entirely satisfactory of 25 patients treated by this method.

(b) Acute syphilitic meningitis. Moore (1946) reported on io cases treated with intramuscular penicillin in total dosage ranging from 600,000 units to $4,000,000$ units given in $7 \frac{1}{2}$ to $I 1$ days. The follow-up was from 287 to 667 days. The immediate symptomatic response was dramatically favourable in every case. Headache and stiff neck disappeared in 24 to 48 hours. Cranial nerve paralysis disappeared in all cases except one in which a slight residuum remained after 98 days. Of four patients with eighth nerve deafness, one showed no improvement (tested by audiometer) after ro4 days. Two patients with convulsions had no further attacks after therapy. Three patients had mild febrile Herxheimer reactions without any clinical exacerbation. The spinal fluid response was entirely satisfactory at the last observation in nine cases, in the tenth case the cells had been reduced from $1,45^{\circ} \mathrm{c} . \mathrm{mm}$. to 9 c.mm. 383 days after treatment, other spinal fluid findings were negative in this case.

In one of the ro cases there was a mucocutaneous relapse 287 days after treatment, which had consisted of only 600,000 units of penicillin in $7 \frac{1}{2}$ days.

The results reported in this group are dramatic when the small dosage of penicillin given in some cases is considered. There is every reason to expect excellent results with present dosage schedules.

Late Syphilis (More Than Four Years After Original Infection)

(a) Asymptomatic neurosyphilis. Penicillin alone 
is used. Hahn (195I) reports in 180 cases with 94.5 per cent. entirely satisfactory response, 5 per cent. unknown and only 0.5 per cent. failure as judged by spinal fluid examination.

(b) Meningeal syphilis (including Erb's spastic paraplegia). In cases in which there is a predominant meningeal reaction, results with penicillin should be adequate except in Erb's paraplegia. Hahn (195I) reports results in nine cases of meningeal involvement of the brain with cranial nerve lesions (excluding optic atrophy and eighth nerve deafness), I I.I per cent. were entirely satisfactory, 44.4 per cent. significantly improved, II.I per cent. results unknown and 44.4 per cent. treatment failures. He also reports 18 cases of spinal cord involvement (including Erb's paraplegia) giving I I.I per cent. entirely satisfactory, 22.2 per cent. significantly improved, 16.7 per cent. results unknown and 50 per cent. treatment failures; when he used malaria in addition to penicillin in three cases there were two failures and one success.

Jones et al. (195I) in a study of I9 patients with non-tabetic spinal cord syphilis observed the best clinical results in five patients with meningo myelitis with a duration of symptoms of less than five months. They stated that the outcome in three patients with Erb's spastic paraplegia or syphilitic amyotrophic lateral sclerosis was discouraging. The duration of symptoms in these patients was of more than one year's duration, and they concluded that considerable degenerative changes had taken place before the onset of therapy. The spinal fluid response in all the cases they reported was comparable to that occurring in other types of neurosyphilis.

(c) Vascular syphilis. Following the occlusion of a medium-sized cerebral or spinal vessel there is always some degree of myelomalacia. As a result of this there is usually little clinical response to therapy.

Jones et al. (195I) describe six patients with acute transverse myelitis as the result of anterior spinal artery thrombosis. None obtained complete clinical recovery after treatment with penicillin. Two of them, however, showed some improvement in motor function and became ambulatory in spite of severe spasticity, they also had fair control of the bladder and anal sphincters. Two patients showed a poor clinical response with but slight improvement of motor function. Two patients showed no recovery and died two months and two and a half years after treatment respectively.

Hahn (195I) reports the results of penicillin therapy in 20 patients with cerebral and spinal vascular syphilis, 20 per cent. were entirely satisfactory, 60 per cent. were significantly improved, in 15 per cent. the results were unknown and 5 per cent. were treatment failures.

(d) General paresis. In this condition, whether occurring as a single entity or combined with tabes dorsalis (tabo-paresis), there remains a difference of opinion as to the necessity of fever therapy in addition to penicillin. Analysis of reported results should be assessed both in relation to spinal fluid reversal and in relation to clinical results in terms of the degree of social recuperation. It may be interesting to compare clinical results obtained by different workers in different countries $\overrightarrow{0}$ in the last few years.

\section{Clinically Cured or Greatly Improved}

(a) Combined penicillin and malaria therapy

Curtis, Kruse and Norton (1949) .. $42 \%$ of 77 cases Lereboullet and Brisset (r949) $\quad . \quad 50 \%$ " 31 ", Nicol and Whelen (195I) .. .. 65\% ", 14I " Lescher and Richards (1947) . $66 \%$ " 15 " Hahn (r95I) .. . . . 67\% " 43 ", Kopp, Rose and Solomon (1948) .. $67 \%$ " 446 ", Kierland, O'Leary and Underwood (1948)

(b) Penicillin therapy alone

Curtis, Kruse and Norton (1949) .. $47 \%$ of 155 cases Hahn (195I) $\quad . \quad \ldots \quad$.. $55 \%$, 70 " Lescher and Richards (1947) . $70 \%$, 10 " Delay, Desclaux and Stevenin (1947) 80 " 95 "

No biostatistical conclusions can be drawn froe this type of comparison. Perlo, Rose, Carme and Solomon (195I) were able to compare two similar groups of patients with advanced simple dementia treated with penicillin only and penicillin plus malaria therapy respectively. They summarize the results in three tables, which are reproduced overleaf.

They concluded that ' clinical results with penicillin alone proved slightly more favourable than those obtained with combined therapy.'

It must be remembered that malarial therapy necessitates admission to a special hospital with skilled medical and nursing care, as there are risks of grave complications and fatalities have been reported. Such a centre exists in this country-The Mott Clinic, Epsom.

Penicillin therapy gives varying results according to the type of psychosis present in paresis. Kopp, Rose and Solomon (1948) report 85 per cent. improvement in patients with slight psychic disturbances, 66 per cent. improvement in affective dementia, but only 25 per cent. improvement in patients with a paranoid psychosis.

Bruetsch considers that total dosage of penicillin in paresis should be more than ro mega units, as he found treponema pallidum still present in the cerebral cortex of patients who came to autopsy after having received this dosage. 
122 PATIENTS WITH ADVANCED SIMPLE DEMENTIA

(after Perlo, Rose, Carmen and Solomon)

Clinical Status

\begin{tabular}{|c|c|c|c|c|}
\hline & & Improved & Arrested & Worse \\
\hline $\begin{array}{l}\text { Penicillin alone, } 30 \text { patients } \\
\text { Combined therapy, } 92 \text { patients }\end{array}$ & $\begin{array}{l}. \\
\ldots\end{array}$ & $\begin{array}{l}19(63 \%) \\
48(52 \%)\end{array}$ & $\begin{array}{r}8(27 \%) \\
25(27 \%)\end{array}$ & $\begin{array}{r}3(10 \%) \\
19(21 \%)\end{array}$ \\
\hline
\end{tabular}

Social Adjustment

\begin{tabular}{|c|c|c|c|c|c|}
\hline & & Good & Fair & Poor & Not known \\
\hline $\begin{array}{l}\text { Penicillin alone, } 30 \text { patients } \\
\text { Combined therapy, } 92 \text { patients }\end{array}$ & & $\begin{array}{r}5(17 \%) \\
13(14 \%)\end{array}$ & $\begin{array}{r}9(30 \%) \\
26(28 \%)\end{array}$ & $\begin{array}{l}15(50 \%) \\
48(52 \%)\end{array}$ & $\begin{array}{ll}1 & (3 \%) \\
5 & (6 \%)\end{array}$ \\
\hline
\end{tabular}

WORK LeVEL

\begin{tabular}{|c|c|c|c|c|}
\hline & & Working & Not Working & Hospitalized \\
\hline $\begin{array}{l}\text { Penicillin alone, } 30 \text { patients } \\
\text { Combined therapy, } 92 \text { patients }\end{array}$ & $\ddot{x}$ & $\begin{array}{l}\text { II }(37 \%) \\
38(41 \%)\end{array}$ & $\begin{array}{r}6(20 \%) \\
16(18 \%)\end{array}$ & $\begin{array}{l}13(43 \%) \\
38(41 \%)\end{array}$ \\
\hline
\end{tabular}

Lastly, there is the problem of the Herxheimer reaction in patients with paresis. Heyman, Sheldon and Evans (1952) reported this in $23\left(5^{2}\right.$ per cent.) of 44 patients with paresis. Six of these 23 patients showed a transient intensification of their psychotic manifestations. Putkonen and Rehtijarvi (1950) studied the Herxheimer reaction in 223 patients with neurosyphilis. All 21 patients in this series with paresis previously untreated showed a febrile response. They stated that previous therapy with arsenic and/or bismuth seemed to reduce this to some extent, while previous malarial or penicillin treatment made the reaction impossible. They also stated that the more active was the spinal fluid the more likely was the febrile response to occur. It usually took place 12 to 16 hours after the first injection of penicillin. They did not experience any serious clinical exacerbations. In a few patients there was increased confusion during the febrile response and in one patient who had previously had fits, a further convulsion occurred at the fever peak. Lereboullet and Sapin Jalloustre (1947) record a patient with paresis who died in status epilepticus after penicillin therapy had been begun and the author has seen a similar case.

(e) Tabes dorsalis. In this condition the problem again arises as to whether penicillin therapy alone is adequate. Hahn (195I) tabulates the results in 70 patients treated with penicillin and 31 with penicillin and malaria. The results in the first group were 41.4 per cent. entirely satisfactory, I8.6 per cent. significantly improved, II.4 per cent. results unknown and 28.6 per cent. treatment failures. In the second group there were 48.4 per cent. entirely satisfactory, I9.4 per cent. significantly improved, 12.9 per cent. results unknown and 19.4 per cent. treatment failures. He con- cludes the effects of penicillin plus malaria therapy on tabetic symptoms are essentially the same as those of penicillin alone. As judged also by overall clinical results the addition of malaria therapy affords no definite benefit. He also states that in a few patients development or progression of symptoms occurs after treatment. Koteen (1949) reported on 403 patients with tabes including 49 treated with penicillin alone. There was improvement of symptoms and signs such as impotence (40 per cent.), ataxia (54 per cent.), lightening pains (50 per cent.), urinary complications (33 per cent.) and paresthesiae (66 per cent.) as indicated. Gastric and other crises, pupillary abnormalities and deep sensibility disorders remained unaffected. The appearance of a new clinical sign such as a Charcot's joint might occur after treatment. Herxheimer reactions are uncommon in tabes according to Putkonen and Rehtijarvi (1950).

(f) Optic atrophy. This serious complication is often associated with tabes dorsalis. If untreated the patient may become blind in three to five years from the onset of symptoms, but the progression of the condition is very variable. One must emphasize the importance of early diagnosis by the examination of the optic discs, visual acuity and visual fields (the earliest change). Klauder and Gross (1949) reported in 56 patients given penicillin and malarial therapy, that there were 32 stabilizations, 10 aggravations and eight became blind. Hahn (I95I) reported progression in six of I7 patients with primary optic atrophy after treatment with penicillin alone, and in three of 16 after treatment with penicillin plus malaria. Blindness occurred in four of the former and two of the latter group. The total period of observation in both groups was only i5 months. Similar types of 
patient composed both treatment groups. $\mathrm{He}$ concludes that penicillin alone cannot yet be evaluated, and penicillin plus malaria remains the treatment of choice.

(g) Gumma of brain or cord. This condition is a clinical rarity and may only be diagnosed at operation as in the case of a gumma of the cord described by Thompson and Preston (1950); their case reponded favourably to penicillin therapy. It has been stated in the past that a serious clinical Herxheimer reaction might occur, especially if the lesion were in the brain below the tentorium cerebelli and that a pressure cone of the medulla might result in a fatality. Premedication with bismuth should always be given as a prophylaxis against this event.

\section{Spinal Fluid Relapse}

Dattner (I949) reported on the spinal fluid outcome of 388 patients with various types of neurosyphilis observed for 6 to 56 months, and recorded only 43 failures to a first course of penicillin. Of these 43 patients, 24 responded favourably to a second course of higher dosage, of the other 19 failures only three showed a continuous active process indicated by persistent abnormal cell count and protein. In I950 Dattner reported concerning further treatment of these three patients (all cases of asymptomatic neurosyphilis). Two had reached an inactive state following treatment with four courses of penicillin totalling 49.8 and 59 mega units respectively. The third case had not been followed long enough to evaluate treatment. In Hahn's (195I) whole series of 589 patients with all types of neurosyphilis, the spinal fluid relapse rate was 1.25 per cent. for the penicillin group and 0.93 per cent. for the penicillin plus malaria group. These relapses only occurred in patients whose initial spinal fluid contained 10 or more cells and who received less than 5 mega. units of penicillin. No patient suffered more than one spinal fluid relapse.

\section{Antibiotics Other Than Penicillin}

There is as yet no evidence that these preparations are more efficient than penicillin in the treatment of syphilis, and they remain considerably more expensive. They have been used experimentally for the treatment of neurosyphilis in a limited number of cases. Kierland and O'Leary (-1950) treated 12 patients with neurosyphilis by giving oral aureomycin and reported satisfactory clinical and spinal fluid reversal. Romansky et al. (195I) treated five patients who had neurosyphilis with chloramphenicol for ${ }_{5} 5$ days. They reported reversal of abnormal spinal fluid cell counts. There was no clinical improvement in a case of tabes dorsalis or in a case of optic atrophy. Robinson
(1952) mentioned an investigation which he was气̊ undertaking with Mohr to study the effect of 3 aureomycin and chloramphenicol in I I patients $\mathbb{\complement}$ with late asymptomatic neurosyphilis (Group $3 c$. spinal fluid changes). The dosage given for both $\vec{\Rightarrow}$ drugs was $60 \mathrm{~g}$. in 15 days. In a graph he showed? the return to normal of spinal fluid cell counts inc I 80 days with a slow improvement in the colloidal $\frac{\bar{c}}{\bar{s}}$. gold curve. The total protein and complement fixation test remained essentially unchanged during this time. He concluded that the treatment of choice for neurosyphilis remained procaine peni- $\overrightarrow{0}$ cillin, 600,000 units daily or every other day to anapproximate total of ro million units.

\section{Summary}

I. In a summary of the present status of treat ment in the various types of neurosyphilis the 0 recent literature concerning clinical and spinalit fluid results has been reviewed.

2. Penicillin appears to be the drug of choice for neurosyphilis; the newer antibiotics have not beeno proved more effective.

The total amount of penicillin given should notc be less than 6 mega units administered in not less? than ro days. Dosage up to 15 mega units in $15 \stackrel{0}{2}$ days is employed in many clinics. The procaine salt of penicillin is generally used with an injectionsc given intramuscularly once in every 24 hous. This makes ambulatory treatment possible.

3. Penicillin alone will give as satisfactory spiral fluid reversal and clinical outcome as when com- $-\frac{\partial}{0}$ bined with malarial therapy except in optic atrophy

4. Where malaria therapy is indicated theo patient should be sent, if possible, to a special? centre where expert medical and nursing care willo reduce the risk of a fatality to a minimum.

5. Spinal fluid relapse rate is low with penicillin therapy and retreatment with a larger dosage is usually successful.

6. The Jarisch-Herxheimer reaction as manifested by a febrile response is not uncommon 3 . especially in general paresis, but serious newi clinical symptoms or exacerbation of existing symptoms are rare. In this country, however, ito is still considered prudent to give 6 to 12 weeks preparatory treatment with intramuscular bismutho before the administration of penicillin in caseswhere there is no urgency. In cases of acutes syphilitic meningitis or in general paresis of acuten onset it may be considered best to give penicillin initially accepting the risk of a clinical Herxheimer reaction.

7. Giving penicillin in initial small dosage which is gradually increased, in no way modifies the incidence or severity of a Herxheimer reaction:Thus when penicillin is administered for neurosyphilis it may be given in full dosage. 


\section{BIBLIOGRAPHY}

BRUUSGaARD, E. (1929), Arch.f. Derm. u. Syph., 157, 309. CURTIS, A. C., KRUSE, W. T., and NORTON, D. H. (1949), Am. F. of Syph. Gonor. E Ven. Dis., 33, 527.

DATTNER, B. (I944), 'The Management of Neurosyphilis,' Grune \& Stratton, New York.

DATTNER, B. (1949), Am. F. Syph. Gonor. \& Ven. Dis., 33, 571. DATTNER, B. (1950), Am. F. Syph. Gonor. E Ven. Dis., 34, 373. DATTNER, B., and THOMAS, E. W. (1942), Am. F. Syph. Gonor. $E^{\circ}$ Ven. Dis., 26, 21.

DELAY, DESCLAUX and STEVENIN (1947), Rev. Neur., July, $5 \times 5$.

FARMER, T. W. (1948), \}.A.M.A., 138, 48.

HAHN, R. D. with assistance of LEWIS, B., WIGGALL, R. H., and CROSS, E. S. (1951), Am. F. Syph. Gonor: E Ven. Dis., 35, 433.

HEYMAN, A., SHELDON, W. A., and EVANS, L. D. (1952), Brit. F. Ven. Dis., 28, 50.

JONES, R. W., HEYMAN, A., SMITH, W. A., and WILSON, R. (1951), Am. F. Syph. Gonor. E Ven. Dis., 35, 72.

KIERLAND, R. R., and O'LEARY, P. A. (1950), Am. F. Syph. Gonor. \& Ven. Dis., 34, 443 .

KIERLAND, R. R., O'LEARY, P. A., and UNDERWOOD, L. J. (1948), Am. F. Syph. Gonor. E' Ven. Dis., 32, 470. KLAUDER, J. V., and GROSS, B. A. (1949), Am. F. Syph. Gonor.
\& Ven. Dis., 33, 234.
KOPP, T., ROSE, A. S., and SOLOMON, H. C. (1948), Am. F. Syph. Gonor. 'E Ven. Dis., 32, 509.

KOTEEN, H. (1949), Am. F. Syph. Gonor. \& Ven. Dis., 33, 364. LANGE, C., and HARRIS, A. H. (1944), Am. F. Pub. Health, $34,1087$.

LEREBOULLET, J., and BRISSET (1949), Rev. Neur., 8, 646. LEREBOULLET, J., and JALLOUSTRE, S. (1947), Bull. Soc. Med. Hop., 26, 775 .

LESCHER, G., and RICHARDS (1947), Brit. Med. F., ii, 565.

MOORE, J. E. (1946), 'Penicillin in Syphilis,' Blackwell, Oxford.

NICOL, W. D., and WHELEN, M. (1951), Brit. F. Ven. Dis., 27, 132.

PERLO, V. P., ROSE, A. S., CARMEN, L. R., and SOLOMON, H. C. (195I), Am. F. Syph. Gonor. E' Ven. Dis., 35, 559.

PUTKONEN, T., and REHTIJARVI, K. (195I), Acta. DermatVenereol., 31, 120.

RAVAUT, P. A. (1903), An. de Dermat et Syph., 4, 537.

REDMOND, A., NICOL, C. S., and SHOOTER, R. A. (1952), Brit. Ұ. Ven. Dis., 28, 13.

ROBINSON, R. C. V. (1952), Brit. F. Ven. Dis., 28, 80.

ROMANSKY, M. J., OLANSKY, S., TAGGART, S. R., LAWDMAN, G.' S., and ROBIN, E. D. (1951), Am. 'F. Syph. Gonor. Es Ven. Dis., 35, 234.

ROSAHN, P. (1946), fournal of V.D. Information Supplement 21.

THOMPSON, R. G., and PRESTON, R. H. (1950), Am. F. Syph. Gonor. E' Ven. Dis., 34, 356.

\title{
FRACTURES AROUND THE ELBOW JOINT IN CHILDREN
}

\author{
By A. W. Lipmann Kessel \\ London
}

The swings and slides of public parks provide our hospitals with a regular week-end clientèle of small boys who have sustained fractures about the elbow joint. The diagnosis of many such fractures calls for nice judgment and a meticulous attention to the general principles as well as the details of treatment. The 1935 Report of the B.M.A. Committee on Fractures did not analyze fractures in children, but if it is true that the average incapacity period for a simple fracture of the clavicle in adults who were not treated in an organized clinic was 22 weeks, as compared to five weeks for those treated in organized clinics, it would be a fair assumption that a similar analysis for the group of more serious and difficult fractures we are now considering would reveal an even greater difference.

Diagnosis and classification. The precise diagnosis of the type of fracture is essential, but by no means always easy because of the complexity of the ossification of the lower end of the growing humerus. Leaving aside for the moment the question of soft tissue damage, this group of fractu res may be broadly classified into five radiological types. Intermediate as well as complex types will, of course, occur. In cases of doubt the opposite elbow must always be X-rayed for comparison:

Supracondylar fractures-extension and flexion varieties.

Transcondylar-simple and ' $T$ '-shaped.

Epicondylar avulsion, with or without dislocation.

Fracture-separation of the external condyle epiphysis.

Fracture of the head or neck of the radius.

Treatment. Each type of fracture will be considered separately, but there are certain general principles applicable to the treatment of all these fractures.

I. Manipulative reduction must always be gentle. Only too often does a complication arise from the violence of attempted reduction rather than from the original injury itself.

2. Wherever possible a 'single attack' should be made to achieve reduction by closed manipulation. It should be carried out under general anaesthesia with $\mathrm{X}$-ray control (not screening), and the several attempts that may be necessary to achieve satisfactory alignment should be carried out at the same session. An examination of some of the disasters which have occurred shows only 